\title{
«LIBERTAD SIN IRA», INDIGNACIÓN EN (LA) TRANSICIÓN: REAPROPIACIONES POLIITICAS Y RELATOS SONOROS DE UN HIMNO PARA LA ESPAÑA DEMOCRÁTICA (1976-2017)
}

"Libertad sin ira», indignation in (the) Transition: Political
(re)appropriations and sonic stories of an anthem
for democratic Spain (1976-2017)

\author{
DIEGO GARCÍA-PEINAZO \\ Universidad de Granada \\ digarpei@gmail.com
}

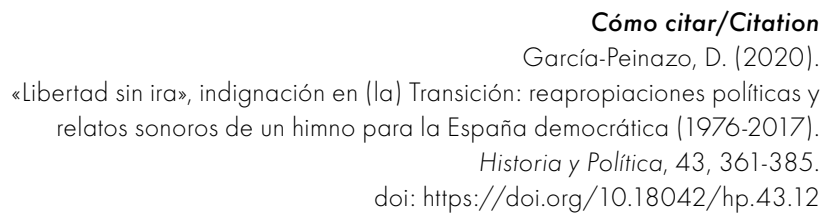

(Recepción: 30/01/2019; evaluación: 02/09/2019; aceptación: 15/11/2019; publicación: 13/05/2020)

Resumen

«Libertad sin ira» se erige como una de las canciones más emblemáticas de la Transición española. Popularizada por el grupo Jarcha, este tema ha logrado articular, durante sus más de cuatro décadas de existencia, discursos y prácticas contrapuestas, vinculadas a destacados acontecimientos políticos y sociales. Tomando en consideración referentes metodológicos del análisis de lo político en música, de la intertextualidad en la canción grabada, así como enfoques teóricos relativos a la idea de la Transición como construcción cultural y sus «relatos», este artículo examina ejemplos de reapropiación musical e instrumentalización política de esta canción desde su aparición en 1976. Tras fundamentar las bases para un análisis político de lo sonoro en "Libertad sin ira», se pasa revista a las rupturas y continuidades en su 
presencia en diversos contextos, desde las movilizaciones por el secuestro y asesinato de Miguel Ángel Blanco por parte de ETA en 1997 a manifestaciones en contra de la política antiterrorista de las legislaturas de J. L. Rodríguez Zapatero, el movimiento $15 \mathrm{M}$ o el procés catalán. No existe, sin embargo, un consenso en torno a la interpretación ideológica de esta canción, y es también objeto de crítica desde la perspectiva de los relatos revisionistas con la denominada cultura de la Transición. Este trabajo evidencia la centralidad de la canción de Jarcha como himno disputado de la España democrática en continua negociación de significados, a través de la pluralidad de memorias y relatos sobre "Libertad sin ira», que incluyen reapropiaciones y lecturas intertextuales, así como negaciones y exclusiones.

\title{
Palabras clave
}

Música popular; política; Transición española; himno; intertextualidad.

\begin{abstract}
«Libertad sin ira» («Freedom without anger») is probably one of the most emblematic songs related to Spanish transition to democracy. Recorded and performed by the band Jarcha, this track has managed to articulate, over the last forty years, opposed discourses and practices which are linked with important political and social events. Following methodological approaches from music analysis and politics, intertextuality in recorded popular song, as well as theoretical approaches to the cultural construction of the idea of Transition to democracy and its different narratives, this paper examines examples of musical re-appropriation and musical instrumentalization of this song since its release in 1976. After dealing with the principles of a political analysis of music in "Libertad sin ira", it is summarized the main continuities and ruptures in its presence in different contexts, such as the mobilizations against the kidnap and murder of Miguel Ángel Blanco by ETA to the demonstrations against the anti-terrorist policies of ex-president J. L. Rodríguez Zapatero's two terms, the $15 \mathrm{M}$ movement or the so-called Catalan procés. There is no consensus, however, around the interpretation of the song ideologies, since "Libertad sin ira" has been also criticized from the point of view of contra-hegemonic narrations of the so-called cultura de la Transición. This paper shows, through a plural range of memories and discourses around «Libertad sin ira»-which include from re-appropriations and intertextual strategies to denials and exclusions - the central role of this song as an «anthem» of democracy Spanish in a constant negotiation of meanings.
\end{abstract}

\section{Keywords}

Popular music; politics; Spanish Transition to democracy; anthem; intertextuality. 
I. UNA CANCIÓN PARA LA TRANSICIÓN. II. DIMENSIÓN POLÍTICA DEL DISCURSO MUSICAL. III. INTERTEXTUALIDAD Y RELATOS SONOROS EN TORNO A «LIBERTAD SIN IRA». IV. SIN CONSENSO SOBRE «LIBERTAD SIN IRA»: DEL MOVIMIENTO 15M AL PROCÉS CATALÁN. V. EPÍLOGO: ¿̇UN HIMNO PARA LA ESPAÑA DEMOCRÁTICA? BiBLIOGRAFÍA.

\section{UNA CANCIÓN PARA LA TRANSICIÓN}

«Libertad sin ira», compuesta por Pablo Herrero y José Luis Armenteros, con letra de Rafael Baladés, fue grabada y publicada por el grupo andaluz Jarcha en 1976. La canción formaba parte de una campaña publicitaria para el lanzamiento de un nuevo periódico español, Diario 16 -del que Baladés era su publicista - que aparecía al calor de los primeros meses tras la muerte de Francisco Franco en noviembre de 1975. La canción fue, desde sus primeros ańos de existencia, un espacio privilegiado para la argumentación política. El 9 de octubre de 1976, pocos días después del lanzamiento de este tema de Jarcha, el director general de Radiodifusión y Televisión, dependiente del Ministerio de Información y Turismo, catalogaba la canción como «no radiable». Una semana después, el 18 de octubre, desde la misma instancia ministerial —y también desde Televisión Española (TVE) — se informó que se trataba de un "error administrativo» ${ }^{1}$. La canción alcanzó gran popularidad en los días que circundaron al denominado Proyecto de Ley para la Reforma Política, celebrado el 15 de diciembre de 1976, y a la altura de junio de 1977, durante las primeras elecciones generales en España tras la dictadura, «Libertad sin ira» se había convertido en la banda sonora de estos comicios.

Desde aquellos años hasta nuestros días esta canción ha venido articulando narrativas y discursos, prácticas e instrumentalizaciones políticas de diverso signo en la Espańa democrática. Su entidad como el himno no oficial de la Transición española $(1975-1982)^{2}$ es constatable, precisamente, por las múltiples vidas de «Libertad sin ira». Su poder evocador de la Transición y la consecución de las libertades es tan notable que ha sido el eje sonoro de

\footnotetext{
«Ira sin libertad», Diario 16, 19-10-1976.
}

2 Siendo conscientes de la amplia discusión teórica al respecto, el uso de la delimitación temporal de la Transición se emplea aquí desde un punto de vista funcional. 
acontecimientos político-sociales destacados en la historia reciente de España, desde su presencia significativa como música de repulsa en relación con los sucesos relativos al secuestro y asesinato del concejal del Partido Popular (PP) Miguel Ángel Blanco por parte de la banda terrorista ETA (1997) hasta las interpretaciones de su estribillo en manifestaciones de diferente signo ideológico. De la misma forma, es parte activa de una política de remix en montajes audiovisuales variados, elaborados por usuarios de plataformas como YouTube: la canción acompaña imágenes a modo del recuerdo y memoria nostálgica de los primeros ańos de la democracia, a finales de los setenta, a la vez que también es objeto de parodia intertextual, como en el caso de "Sin WhatsApp, sin WhatsApp", sketch presentado en Aragón TV en $2013^{3}$.

Sin embargo, esta canción también ha sido observada de forma crítica, tratada con recelo y analizada como el resultado de una forma concreta de entender el proceso de la Transición sustentada en una lógica del consenso que propicia el olvido de la memoria de la Guerra Civil y el franquismo. No es tan solo objeto de mirada nostálgica de una Transición modélica, sino también entendida como icono del borrón y cuenta nueva. "Libertad sin ira» conforma, por tanto, un lugar del pasado capturado en forma de fonograma y en cuyos surcos se disputan ideas y valores contrapuestos sobre la idea de la España democrática.

\section{DIMENSIÓN POLÍTICA DEL DISCURSO MUSICAL}

Las razones por las cuales una canción se convierte en emblemática de un periodo de la historia de un país son múltiples y atienden a factores de naturaleza diversa, negociados desde diferentes agentes musicales, culturales, sociales y políticos. Para Collado Seidel, himnos y canciones se vertebran como símbolos de las identidades colectivas en torno a la idea de la «música nacional», pudiendo estos ser articulados «desde abajo» o «desde arriba», esto es, tanto por los discursos y las prácticas (musicales) ciudadanas como por «procesos racionales» de las élites ${ }^{4}$. De la misma forma, Sandie Holguín

3 «Sin WhatsApp, sin WhatsApp», de Aragón TV (2013), disponible en YouTube: https://bit.ly/2HiFNS0 (fecha de consulta: 29-1-2019). Véase, asimismo, «Ese loco material», canción parodia del grupo Los Gandules (2013) sobre el tema «Libertad sin ira», disponible en YouTube: https://bit.ly/2w5FU0V (fecha de consulta: 29-102019).

4 Collado Seidel (2016): 3-4. Este trabajo no recoge, sin embargo, ningún estudio dedicado a «Libertad sin ira». 
sostiene que en España, a lo largo del siglo xx fueron habituales los debates, «batallas» y disputas en torno a la construcción, definición y promoción de una identidad nacional mediante proyectos culturales centrados en la música y las performances musicales 5 . Esteban Buch, quien ha dedicado una parte importante de sus investigaciones a las relaciones entre música y política y, en concreto, a los himnos políticos, sugiere que estos pueden ser utilizados tanto para la manifestar la oposición como para mantener el orden establecido por medio de la acción del Estado. Esta tendencia es conceptualizada por Buch en torno a lo que denomina como «música de estado», esto es, aquella "música reconocida como gesto o discurso político, cuya producción o interpretación tienen lugar por acción del estado» ${ }^{6}$.

En el caso de "Libertad sin ira», atendiendo a factores culturales, identitarios y políticos, cabría destacar, en primer término, su ubicuidad dentro de algunos de los imaginarios, discursos y prácticas en torno a la Transición, esto es, los vinculados a la «matriz cultural» de la democracia y a sus mitos fundacionales como nación tras la muerte del dictador. Jorge A. Benedicto emplea el término «matriz cultural» de la democracia española en base a la recurrencia de rasgos como "la centralidad y legitimidad de la que disfruta la democracia como sistema político en las representaciones compartidas sobre la vida política [...] unas raíces vinculadas al marco simbólico de la necesidad e inevitabilidad de la democracia (...) la debilidad de las relaciones de los ciudadanos con el sistema político [...] [y] la existencia de una visión limitada de la participación [...]»

La relación de esta matriz cultural de la democracia española con la canción "Libertad sin ira» como himno no oficial de la Transición es clara en tanto entraña una serie de significados compartidos de efectiva evocación de las ideologías que articula dicha matriz en la ciudadanía. Por otro lado, siguiendo a Sebastián Balfour y Alejandro Quiroga, dentro de los mitos fundacionales de España después de la Transición a la democracia destaca aquel vinculado a la reconciliación, el consenso y la tolerancia entre españoles en contraposición al imaginario romántico de España como pueblo «apasionado y fratricida» con continuos enfrentamientos civiles ${ }^{8}$. Así, frente a la importancia del mito antifascista en otras naciones europeas como Francia o Italia, en España, debido a la forma en la que se llevó a cabo el paso del franquismo a la democracia, fue la idea de «la reconciliación, el consenso y el entendimiento

\footnotetext{
5 Holguín (2017): 219. Sobre música y nación en la España contemporánea, véase, asimismo, Alonso (2010).

6 Buch (2001): 10.

Benedicto (2015): 182.

8 Balfour y Quiroga (2007): 83.
} 
pacífico entre españoles, y no la lucha antifranquista, los que pronto se convirtieron en símbolos de la nueva identidad democrática española»9.

Aunque no sea posible presentar aquí un estado de la cuestión detallado de las diferentes investigaciones sobre música y Transición democrática en España, nótese que durante el espacio de tiempo que va desde 1975 y 1985 convivieron diferentes géneros y escenas musicales académicas y populares que se entreveraron con lo político de manera diversa ${ }^{10}$. Con el transcurso de los años, algunas de estas músicas, históricamente vinculadas a procesos de politización explícita durante el tardofranquismo, perdieron presencia mediática y peso en las industrias culturales, como el caso de los cantautores, mientras otras músicas vinculadas a las estéticas de la Movida se erigieron como discursos que tornaron de emergentes a hegemónicos.

Jarcha, que había iniciado su carrera musical en la primera mitad de los setenta, puede enmarcarse en el movimiento del neofolk, asociado habitualmente a agrupaciones musicales con una prominencia del canto a varias voces y cuyas prácticas se vinculaban a la musicalización de textos de insignes poetas, así como a temáticas cercanas a los discursos de lo tradicional. Las sonoridades del neofolk fueron, sin duda, un referente para la composición de músicas electorales de la segunda mitad de los setenta en Espańa, no solo por la presencia de grupos como Jarcha en el contexto político de la época, sino a través de composiciones escritas exprofeso, a la manera de jingles, para su inclusión en campañas políticas para las elecciones de 1977 y 1979 — sin ir más lejos, el jingle «Vota centro, vota Suárez» conserva esa sonoridad neofolk-. En este sentido, "Libertad sin ira» no fue, sin embargo, la única canción asociada a las primeras elecciones legislativas.

«Habla, pueblo, habla» (1976), canción compuesta por Álvaro Nieto e interpretada por el grupo Vino Tinto, fue potencialmente representativa de aquellos primeros pasos de la democracia. Su música sirvió como publicidad para promocionar el referéndum sobre el Proyecto de Ley para la Reforma Política, celebrado el 15 de diciembre de 1976, una campaña "por el sí»

$9 \quad$ Balfour y Quiroga (2007): 87-88.

10 Sobre las diferentes prácticas musicales: escenas de la Movida, véanse Fouce (2006, 2009) y Fouce y Val (2013); cantautores, véase Pérez-Villalba (2007); músicas académicas, véase Medina (2010); discurso y metáforas políticas del PSOE y el PCE en relación a músicas académicas y populares a través de sus órganos de expresión, véase García-Peinazo (2012; 2014); rock en distintos nacionalismos subestatales, véanse García-Peinazo (2017), García Salueña (2017) y Val (2017a, 2017b). Destacan también algunos estudios de caso, como el del binomio Alfonso Guerra-Gustav Mahler en la Transición (Solís Marquínez, 2018). 
promovida por Adolfo Suárez en la cual incluía la canción de Vino Tinto y a diversos de sus integrantes interpretándola. En esta coyuntura, la banda sostuvo que se produjo una instrumentalización política de su música: «Lo que nosotros desconocíamos es que nuestras voces iban a ser utilizadas para inducir al voto en un referéndum que no aprobamos» ${ }^{11}$.

En la actualidad, se sigue recurriendo a «Habla, pueblo, habla» para explicar los procesos electorales de aquellos años, como constatan exposiciones como «Habla, pueblo, habla», instalada en el Congreso de los Diputados durante el otoño de 2017, cuyo fin fue conmemorar los cuarenta años de las primeras elecciones democráticas ${ }^{12}$. Sin embargo, la canción de Vino Tinto no ha sido objeto de reapropiaciones significativas con el paso de los años. «Libertad sin ira», por el contrario, ha sobrevivido a sus propios usos y funciones emblemáticas iniciales, pasando de ser, sensu estricto, objeto de una campaña promocional de un periódico a representar la Transición y los ideales de libertad y democracia para, en décadas posteriores, ser un fetiche en ciertas movilizaciones políticas y ciudadanas.

El discurso musical, esto es, el texto sonoro, es decisivo en la conformación de imaginarios y la articulación de discursos y prácticas políticas. Analizar lo político en la canción popular no es tan solo, como puede intuirse, un asunto que concierna a lo que su letra nos cuenta o lo que las culturas y poderes políticos desarrollen en torno a la misma, enfoques que, sin embargo, suelen ser predominantes en las investigaciones que tratan de tender puentes entre música y política ${ }^{13}$. El hecho de que la letra de «Libertad sin ira» describa la situación en la que España se encontraba en aquellos años - la guerra civil, la idea de las dos Españas, la violencia, las ansias de democracia, paz y libertad durante la Transición - es, obviamente, algo que favorece su identificación con lo político. También lo es, por descontado, su instrumentalización política por parte de diferentes grupos ciudadanos, poderes e instituciones ${ }^{14}$,

11 «Rechazamos la manipulación», Diario 16, 10-12-1976, p. 7.

12 Exposición «Habla, pueblo, habla», Congreso de los Diputados (2018), disponible en: https://bit.ly/2Sk61tN (fecha de consulta: 1-12-2018).

13 Una excepción a este respecto se encuentra en el estudio de las relaciones entre análisis musical y política desarrollado por Buch et al. (2016). Véase también Buch y Donin (2013).

14 A este respecto, Igor Contreras, en su análisis sobre el denominado Concierto de la Paz (1964) llevado a cabo durante el franquismo y la posición ideológica de los compositores que participaron en este evento, se muestra crítico con la posibilidad de lecturas reduccionistas sobre un enfoque de estudio de la instrumentalización política de la música que no contemple el posicionamiento inicial de los músicos ante las obras al servicio de actos institucionales. Este musicólogo sostiene que «es difícil disociar las 
como se desarrolla más adelante. Sin embargo, el cómo se canta y lo que envuelve a lo que es cantado son dos elementos nucleares en la creación de sentido en la cultura popular, afectando de manera decisiva en el resto de planos de significación de lo político en la música.

Dario Martinelli, en su estudio sobre lo que define como «canción de protesta social» (song of social protest), determina que este conglomerado de repertorios puede ser conceptualizado bajo la idea de "género musical» atendiendo, por una parte, al contenido de sus letras, que recogen grandes ideales planteados desde la Ilustración, como los derechos humanos, la igualdad o la libertad, independientemente del activismo político del cantante. Por otro lado, Martinelli sostiene que se trata de músicas funcionales, ya que sus canciones tienden a ser fácilmente memorizables y pueden interpretarse por personas sin un bagaje musical previo ${ }^{15}$. Así, plantea como características definitorias de esta tipología de canciones la simplicidad y sencillez en la instrumentación (guitarras acústicas o palmas, por ejemplo), en la armonía y en las estructuras rítmicas, así como el uso de estribillos y temas melódicos pegadizos, unido a un «sonido culturalmente connotativo de lo social» (atmósfera folk o «étnica», feeling acústico, etc. $)^{16}$. Sin embargo, a pesar de que el autor no contempla en su clasificación aspectos relativos a la producción musical, consideramos que estos elementos también construyen este tipo de canciones.

"Libertad sin ira», de acuerdo con lo anterior, puede considerarse un tipo de «canción de protesta social». Las estrofas están cantadas por su vocalista principal, Ángel Corpa, a la manera de un cuento sobre la historia de España («Dicen los viejos [...]»), esto es, situando la nación en la narración. En la grabación, desde una dimensión proxémica de la producción musical, este cantante está al frente de la mezcla, esto es, su voz, que se acompaña tan solo del piano, está espacialmente cercana a nosotros cuando escuchamos la canción ${ }^{17}$. Canta, por momentos, con una expresión vocal cercana al espacio de lo íntimo porque narra los acontecimientos con la precaución con la que pueden expresarse las reivindicaciones frente los temores y los miedos de un cierto sector apocalíptico con la transformación y el cambio a los que hace referencia. Sin embargo, en el pre-chorus (pre-estribillo) aparecen no solo el

obras musicales de los eventos políticos en torno a ellas, a pesar de los intentos de situar la música más allá de la dimensión política, abanderar la idea de la libertad musical, reivindicar la disociación entre arte y política y denunciar la apropiación de obras con propósitos ideológicos» (traducción propia), Contreras (2016): 183.

15 Martinelli (2017): 9.

16 Ibid.: 9-10.

17 Sobre proxémica y producción en la canción popular grabada, véase Moore (2012). 
resto de los instrumentos del conjunto — guitarras, bajo y batería-, sino también voces que se oponen a dicha descripción apocalíptica del país ("Pero yo solo he visto gente [...]»), primero tímidamente - esto es, a una intensidad débil-, pero ganando progresivamente presencia hasta alcanzar su mayor intensidad en la palabra "paz», justo antes del estribillo.

Si en su estribillo proclama "Libertad, libertad, sin ira, libertad», hay que tener presente que este aparece como un fragmento coral, en el cual voces de hombres y mujeres afirman, en colectivo y con armonía a varias voces —una suerte de consenso entre diferentes tendencias $-{ }^{18}$, que se destierre la ira, el miedo, ya que la libertad está y «si no la hay, sin duda, la habrá». Nótese que, en dicho inicio del estribillo, sobre la palabra «libertad» se entona una melodía con un intervalo inicial de cuarta justa ascendente, esto es, un salto entre dos notas, mi («Li-ber») y la («-tad»), y este intervalo es el mismo al que recurre, por ejemplo, el inicio de La marsellesa («Allons enfants [...]»), pudiendo entenderse bajo el término de musema, esto es, una unidad mínima de significación musical ${ }^{19}$. La canción también cuenta con un componente participativo evidente, si se prefiere, una estrategia de interpelación musical con la ciudadanía como potencial oyente. Tras repetir tres veces el estribillo se produce una súbita suspensión rítmica y un cambio de tono para que tan solo escuchemos al grupo, la colectividad, recitando el estribillo mientras se escuchan palmas, volviendo posteriormente a incorporarse el resto de los instrumentos. Esta ficcionalidad de una actuación en directo - el instante en el cual el grupo deja que sea el público quien coree el estribillo- articulada en el estudio de grabación, como «refractación de la autenticidad ${ }^{20}$ de la interpretación en vivo, se acerca poderosamente a lo que podría cantarse en una concentración ciudadana ${ }^{21}$.

\section{INTERTEXTUALIDAD Y RELATOS SONOROS EN TORNO A «LIBERTAD SIN IRA»}

La Transición a la democracia, como proceso histórico y político, conforma uno de los imaginarios más poderosos en la Espańa de las cuatro

18 Lo armónico constituye uno de los ejemplos más recurrentes de metáfora política a través de la música, ya que «la armonía es una metáfora frecuente para la resolución de conflictos», O’Connell, (2010): 5. Véase, asimismo, Urbain (2008).

19 Sobre la definición de musema, véase Tagg (2013): 232-237.

20 El concepto de refractación de la autenticidad es desarrollado por Grau Rebollo (2015).

21 Un estudio pionero sobre las expresiones sonoras colectivas en manifestaciones en la calle se encuentra en Ayats (1997). 
últimas décadas. Las formas de imaginar este periodo, presentes en narrativas mediáticas, en el discurso político o en las expresiones artísticas, entre otras, difieren en la lectura ideológica de dicho proceso, en un amplio rango de posiciones, desde visiones celebratorias sobre una Transición modélica, fruto del consenso, hasta perspectivas críticas e incluso negacionistas en diferente grado, incluidos estudios que proponen la necesidad de una ruptura con el mito pacífico de la Transición ${ }^{22}$. Gonzalo Pasamar sostiene que «la Transición [...] ha sido objeto, hasta hoy, de un proceso de "historización" que se remonta a los años en que tuvo lugar el fenómeno [...] desde entonces se viene asistiendo a la aparición de una serie de narrativas y un sinfín de representaciones acompañadas de una evaluación del hecho histórico y de propuestas de futuro ${ }^{23}$. Este historiador, en su estudio sobre lo que denomina «relatos escépticos» sobre la Transición española —opuestos a las visiones modélicas u oficiales de la Transición- delimita tres componentes fundamentales de tipo político en torno a los que estas se estructuran, como son los proyectos de reforma, las ideas de ruptura y el denominado «desencanto». El soporte de estos relatos, como evidencia Pasamar, puede ser un comentario político, una película o una novela. La música de Jarcha, por supuesto, no ha estado al margen de estos relatos, ya sea entendiendo la Transición como proceso histórico fundacional de la democracia, ya sea reinterpretando los imaginarios de la libertad en otras latitudes o dotando a "Libertad sin ira» de un poder articulador de simbologías frente a acontecimientos violentos en el país durante la democracia.

«Libertad sin ira» ha operado como un dispositivo de recuerdo de un proceso histórico y político como el de la Transición a la democracia. «Memoria sin ira» fue el nombre de un capítulo dedicado a Jarcha de la serie Vivir cada día, de TVE, publicado cuando diez años habían pasado de manera sońolienta desde aquella primera vida de la canción. Este documental recoge, entre otras, actuaciones de Jarcha en el festival Andalucía Abierta, celebrado en Sevilla el 20 de marzo de $1987^{24}$. Ejemplos más recientes, como el de la serie de Televisión Española Cuéntame cómo pasó — dedicada a la historia reciente de España a través de las narraciones de vida cotidiana—, revisitaban esta canción empleando imágenes que pasan del conflicto bélico de la Guerra Civil española a las manifestaciones ciudadanas durante la Transición ${ }^{25}$. El

22 Véase Baby (2018).

23 Pasamar (2018).

24 J. L. Montoya: «El grupo Jarcha, nuevamente junto convocado por García Pelayo», ABC Sevilla, 7-3-1987: 59.

25 Cuéntame cómo pasó. Temporada 10, capítulo 162 (2008), RTVE a la carta, disponible en: https://bit.ly/31K4JLR (fecha de consulta: 12-01-2019). 
Museo Adolfo Suárez y la Transición, localizado en Cebreros (Ávila), lugar de nacimiento del primer presidente del país tras la muerte de Franco, cuenta con una sección en la cual puede escucharse en pequeñas cabinas canciones representativas de aquella época, entre ellas «Habla, pueblo, habla» o «Libertad sin ira», y son estos prácticamente los únicos espacios relacionados con aspectos culturales de la Transición ${ }^{26}$. Este museo organizó, el 13 de octubre de 2018, el concierto 40 Años de Constitución, con motivo del cuarenta aniversario de la Constitución de 1978. En el mismo, el Coro Polifónico de Cebreros interpretó obras como «Libertad sin ira»"

Un cover o versión de una canción como "Libertad sin ira» también puede constituir un relato sonoro sobre la transición a la democracia como proceso. Esta práctica o ejercicio de versionar, implícita o explícitamente, articula nuevas visitas nostálgicas por parte de bandas musicales, audiencias y fans para legitimar perspectivas ideológicas y experiencias estéticas. Siguiendo a Rubén López-Cano, una versión implica «una experiencia de escucha. Es la instauración, por parte de un oyente, de una relación entre una canción considerada como punto de origen o referencia y otra entendida como su actualización $»^{28}$. En este sentido, el grupo madrileño de rock Los Porretas grabó en 2017 una versión de «Libertad sin ira» dentro de su álbum Clásicos II. Teniendo en cuenta la centralidad del rock urbano y el punk-rock en su música, el grupo tuvo que justificar ante los medios el porqué de la elección de esta canción. Bode, cantante y guitarrista de la banda, sostiene que «Clásicos I eran temas más de rock de nuestro rollo, pero aquí hemos querido coger otro tipo de canciones y llevarlos [sic] a nuestra manera de hacer las cosas». Los Porretas sostienen que el conjunto de canciones que conforman el disco, incluida "Libertad sin ira», tienen la coherencia de «reivindicar la libertad» en diferentes periodos históricos: «Hubo unos años en los que la gente pedía libertad y parecía que se había conseguido algo, pero estamos otra vez en un momento que parece que se están cortando. Hay canciones de estas que parecen casi más actuales casi que cuando se escribieron ${ }^{29}$. La libertad, por tanto, se convierte en una categoría intertextual vinculada a la archifonografía. Asimismo, Los Porretas, con su

Sehrt y Reckling (2013): 108.

27 Coro Polifónico de Cebreros. (2018). Concierto 40 Años de Constitución, Museo Adolfo Suárez y la Transición, disponible en: https://bit.ly/2tU4Gk4 (fecha de consulta: 06-12-2018).

28 López-Cano (2012): 83.

29 David Gallardo: «Porretas: "Julio Iglesias y José Luis Perales eran nuestros ídolos de críos"». Europa Press, 13 de marzo de 2017, disponible en: https://bit.ly/39woyJh (fecha de consulta: 17/12/2018). 
versión de «Libertad sin ira»—un ejercicio de tipo hiperfonográfico-, apelan, por una parte, a la Transición como tiempo pretérito en el que se luchó por las libertades y, por otro, esta canción sirve para denunciar injusticias del tiempo actual de la banda ${ }^{30}$.

Esos imaginarios sobre la libertad en «Libertad sin ira», canción inicialmente compuesta y escrita para ser contada en la Espańa de la Transición, también fueron reapropiados en otros contextos y latitudes. El 27 de noviembre de 1983, en plena dictadura cívico militar en Uruguay, se vivió en torno al Obelisco de Montevideo un día histórico de movilización ciudadana, recordado popularmente como «río de libertad». Jaque, revista semanario uruguaya, situaba en su portada los versos «Libertad, libertad / sin ira libertad / guárdate tu miedo y tu ira», al lado de una fotografía en la que un ciudadano de la tercera edad portaba una pancarta en la que podía leerse «No moriré sin democracia $»^{31}$. En efecto, esta canción - junto a otras vinculadas a artistas de la nueva canción en Uruguay como Alfredo Zitarrosa o Los Olimareńosfue utilizada de forma masiva en dicha manifestación, como relata una crónica en las páginas interiores de este semanario: «Por los altoparlantes se repitió varias veces una canción de Jarcha, ovacionada y recibida con alegría cada vez que se repetía " $^{32}$. Si durante esta movilización multitudinaria se corearon eslóganes como "Libertad, Libertad", "Se va a acabar la dictadura militar", "Uruguay, Uruguay"»33, el estribillo de la canción objeto de nuestro estudio, empleada unos cinco años atrás como emblema de un proceso de transición a la democracia, servía como referente transnacional para la defensa de las libertades políticas en Uruguay.

Marita Fornaro ha estudiado la presencia de las filiaciones entre España y Uruguay en la música popular entre 1972 y 1985, demostrando la importancia de canciones como "Libertad sin ira», "A galopar» (música de Paco Ibáńez sobre un poema de Rafael Alberti) o «Para la libertad» (música de Serrat sobre un poema de Miguel Hernández), que «fueron reapropiadas por un público que se constituye en una comunidad con una identidad de resistencia ${ }^{34}$. Aunque no aborda el caso específico de la utilización de la canción de Jarcha en la citada manifestación del 27 de noviembre de 1983, atestigua diversos

30 Sobre las tipologías transfonográficas vinculadas a la teoría de la intertextualidad y transtextualidad de Gérhard Genette aplicada a la canción grabada, véase Lacasse (2018).

31 Jaque: Revista Semanario, Portada, 1 (3), del 2 al 8-12-1983.

32 Petit (1983).

33 Ibid.: 17.

34 Fornaro Bordolli (2012): 66. 
«espacios de resistencia» en los que se usó esta canción durante la década de 1980: «[...] en el "periodo de apertura", algunos estadios de fútbol se constituyeron en territorios de la resistencia, muchas veces alcanzados luego de una marcha que llenaba las calles de la ciudad de Montevideo con música contestataria, uruguaya o tomada de otros países, como es el caso del tema "Libertad sin ira" $"$ ". Por su parte, Esteban Teo Valenzuela ha registrado cómo, durante la dictadura militar chilena de Augusto Pinochet (1973-1990), formaciones políticas por entonces clandestinas, tales como el Movimiento de Acción Popular Unitaria (MAPU), emplearon en actos la canción «Libertad sin ira»" ${ }^{36}$.

$\mathrm{Si}$ bien los casos anteriores ejemplifican el potencial de las relecturas intertextuales de esta canción, de entre todos los relatos en torno a «Libertad sin ira», su relación simbólica con lo acontecido en torno al terrorismo de ETA ha sido, sin duda, uno de los espacios más destacados en la construcción del imaginario sonoro de la España de las últimas décadas, especialmente significativa a finales de la década de 1990. El 13 de julio de 1997, ETA asesinaba, tras tres días de secuestro, a Miguel Ángel Blanco, concejal del Partido Popular por Ermua (Vizcaya). La movilización ciudadana que se desarrolló en el país en repulsa al terrorismo, sin precedentes en el país, estuvo marcada significativamente por la música del grupo Jarcha.

En su estudio de caso sobre las interacciones entre movilización colectiva y medios de comunicación vinculadas al secuestro y posterior asesinato de Blanco, Teresa Sádaba Garraza sostiene que aconteció «una amplia cobertura y una movilización social sin precedentes ${ }^{37}$. Esta investigadora destaca la movilización de más de seis millones de personas en concentraciones localizadas en distintos puntos del país, que «asume experiencias previas, fusionada con la espontaneidad lógica de un movimiento masivo y no reclutado ${ }^{38}$. Desde la perspectiva del framing, Sábada Garraza destaca cinco símbolos principales que articularon la idea de unidad en las concentraciones, que combinaban con efectividad «resonancias culturales con estrategias movilizadoras», aspectos a los que los medios de comunicación prestaron especial atención: «el lazo azul», «las manos blancas», «las fotos del secuestrado y asesinado», «las velas»y «Libertad sin ira»" Sobre este último, Sábada Garraza apunta

\footnotetext{
35 Fornaro Bordolli (2014): 62.

36 «Paz Egaña Barahona, la menor de los hermanos mapucistas e izquierdistas cristianos, cantaba en los actos: "Libertad, libertad, sin ira, libertad"». En Valenzuela (2014): n.18.

37 Sábada Garraza (2004): 66.

38 Ibid.: 72.

39 Ibid.: 73.
} 
que «recuperada de los tiempos de la Transición [...] significa toda una postura de las movilizaciones de aquellos días, en las que se vienen a recuperar los valores propios de la libertad y de la democracia frente al fascismo. De la misma manera que en la Transición, supone el civismo de las acciones ciudadanas que reclaman libertad. A la vez era todo un signo de unidad popular contra las imposiciones de la banda terrorista ${ }^{40}$.

En los días previos al asesinato de Miguel Ángel Blanco, «Libertad sin ira» se posicionó con efectividad como una canción emblemática que apelaba simbólicamente en su estribillo a la no violencia y a la liberación del concejal que, finalmente, no se produjo. Ángel Gonzalo, periodista de Amnistía Internacional, declaró en un programa radiofónico dedicado al País Vasco a través de canciones que esta agencia pedía «una agenda de derechos humanos y reconocimiento para todas las víctimas del conflicto» ${ }^{41}$, que «"Libertad sin ira" se convirtió en un himno contra la barbarie de ETA [...], una canción que no consiguió su objetivo, que era detener el asesinato de Miguel Ángel Blanco, pero sí que algo cambió en la sociedad a partir de ahí» ${ }^{42}$. Ángel Corpa, vocalista de Jarcha, reforzaba en una entrevista en 2015 ese potencial espontáneo del tema: «Que una canción fluya espontáneamente casi en todas las ciudades de España, como sucedió con el caso de Miguel Ángel Blanco, es algo que a mí me dejó muy impactado» ${ }^{43}$. Asimismo, el líder de Jarcha recordaba, en una entrevista en 2017, que «la canción se puso espontáneamente de nuevo en la boca de la gente que llenaba a millones las calles y las plazas de España protestando contra aquella barbarie, con aquel grito de "Basta ya"». ${ }^{44}$

El 10 de septiembre de 1997, RTVE organizó el macroconcierto Unidos por la Paz y la Libertad en la madrileńa Plaza de las Ventas, e informaba así en el telediario de esta cadena tras la celebración del mismo: «La música, a través de la participación de diferentes artistas, ha sido el nexo

\section{Ibid.}

41 Véase descripción argumental textual del programa radiofónico en Coordenadas. Euskadi en la agenda, 23-3-2017, RTVE a la carta, disponible en: https://bit. ly/38msPPh (fecha de consulta: 18-12-2018).

42 Ibid., entre el 37'03" y el 39'00" del citado podcast.

43 "Ángel Corpa: "Indignación es la palabra que mejor define el país"». La Región. Orense, 16-5-2015, disponible en: https://bit.ly/2w2Q4PV (fecha de consulta: 17/12/2018).

44 G. Muñoz y A. Martínez: Jarcha pone música a «Hablemos», el poema de Benjamín Prado sobre Cataluña. La Ventana, Cadena Ser, 4-12-2017 [podcast], entre el 13'25” y el 15'21" del audio, disponible en: https://bit.ly/39wVG3h (fecha de consulta: 18-12-2018). 
para exteriorizar la unidad de todos, ciudadanos y políticos frente a la sinrazón etarra $»^{45}$. Además de ser utilizado el estribillo de "Libertad sin ira» como sintonía del programa especial dedicado a este concierto por parte de TVE, el grupo Jarcha fue el encargado de cerrar el evento con esta canción, interpretada dos veces seguidas y cantada por las audiencias asistentes y por representantes políticos. "Libertad sin ira» se convertía, por momentos, en un claro ejemplo de música de Estado.

Sin embargo, algunos sucesos acaecidos en este acto fueron significativos de las tensiones políticas del momento. El cantautor Raimon fue abucheado en este concierto por cantar en catalán. Como respuesta, el siguiente invitado al escenario, el actor José Sacristán — quien también fue abucheado en la lectura del poema «Y por mí vinieron», atribuido a Brecht, al citar la palabra «comunista»-, denunció ante el público: «No sé desde qué extraño sentido de la libertad se silba a alguien que habla en su idioma» (55’12”), marchándose del escenario. Por otra parte, diarios como El País harían de altavoz de las desavenencias de representantes de formaciones políticas como el Partido Socialista Obrero Español (PSOE) e Izquierda Unida (IU), que criticaban la politización del acto por parte del Partido Popular, que gobernaba el país desde el año anterior, $1996^{46}$.

\section{SIN CONSENSO SOBRE «LIBERTAD SIN IRA»: DEL MOVIMIENTO 15M AL PROCÉS CATALÁN}

Quizá sea esa la clave: haber sido un cauce por el que han circulado todas las cosas que nos han ido pasando desde que la canción se puso en el viento allá por 1976, que era un momento en el que estábamos amaneciendo a las libertades y la democracia, hasta el golpe tan brutal que supuso el secuestro y posterior asesinato de Miguel Ángel Blanco 21 años más tarde (Ángel Corpa, líder de Jarcha) ${ }^{47}$.

45 Telediario TVE, 10-9-1997, disponible en: https://www.youtube.com/watch?v=6RJLlbaVXc4 (fecha de consulta: 18/12/2018).

46 Javier Casqueiro: «Críticas al PP por convertir el homenaje a Miguel Ángel Blanco en un concierto partidista", El País, 12-9-1997, disponible en: http://bit.ly/2T8JHm3 (fecha de consulta: 18/12/2018). Véase también Pablo Ordaz: «Bochorno por los insultos a Raimon y Sacristán», El País, 12-9-1997, disponible en: https://elpais.com/ diario/1997/09/12/espana/874015211_850215.html (fecha de consulta: 18/12/2018].

47 En Nuria Lozano: “Libertad sin ira” es lo más hermoso que me ha pasado». Las noticias de Cuenca, 27-12-2017, disponible en: http://bit.ly/38TuvzN (fecha de consulta: 19/12/2018). 
Pero las relecturas políticas sobre «Libertad sin ira» han persistido. Las dos últimas décadas en España (2000-2019) atestiguan una resignificación y revitalización notables, que continúan con la tendencia de esta canción a articular relatos políticos diversos. Esto incluye instrumentalizaciones que pasan tanto por la reapropiación simbólica como por su no inclusión o abierto rechazo, ambas con intencionalidad política. Dentro de las reapropiaciones, algunas de estas prácticas políticas con "Libertad sin ira» se emparentan con las tipologías descritas en el punto anterior - como proceso de la Transición española, como discurso transnacional de libertad o como repulsa a la violencia terrorista-, mientras que otras crean nuevas filiaciones con modelos ideológicos, grupos ciudadanos y colectivos sociales. Por su parte, la omisión o la oposición política abierta a esta canción se vehicula fundamentalmente con los relatos contrahegemónicos sobre el proceso de la Transición, revitalizados especialmente a partir de las movilizaciones ciudadanas del $15 \mathrm{M}$, también conocido como movimiento de los indignados. Así, siguiendo con la idea de la «matriz cultural» de la democracia desarrollada por Benedicto, la emergencia de la crisis económica en España produce también una crisis de dicha matriz cultural de la democracia, en un periodo dominado por «la desafección institucional y la indignación popular» ${ }^{48}$.

A la altura de 1894, el cubano José Martí, quien sentaría las bases ideológicas para la independencia de Cuba como colonia española, escribía las palabras «sea nuestro lema: libertad sin ira» en su publicación «El tercer año del Partido Revolucionario Cubano" para el periódico Patria ${ }^{49}$. En 2018, la canción «Libertad sin ira» fue el motor de una dramatización escolar amateur en Venezuela sobre la muerte de Simón Bolívar, que se escenificaba con partes en las que sobre la base grabada de la canción se presentaban, a modo de karaoke, partes cantadas con adaptaciones de su letra: «Dicen los viejos que en este país hubo una guerra, y hay dos "Venezuelas" que guardan aún el rencor de viejas deudas $»^{50}$. Venezuela y «Libertad sin ira» también fue un binomio al que se recurrió en la Convención Nacional del Partido Popular (PP) en 2015, en la cual esta formación política arremetió contra Podemos, partido político de izquierda nacido el año anterior y que empezaba a ganar fuerza, por sus

\footnotetext{
48 Benedicto (2015).

49 Véase el compendio de este y otros escritos en Martí (2013): 204. Ejemplos como el libro Libertad sin ira: Secretos y Curiosidades Martianas (García, 2017) evidencian la iconicidad de esta expresión en el ideal de liberación de Martí.

50 Véase dicho fragmento audiovisual en la plataforma YouTube, Dramatización muerte del libertador "Libertad sin ira", disponible en: https://www.youtube.com/watch?$\mathrm{v}=$ NWN7DPKEzbU (fecha de consulta: 12/12/2018).
} 
supuestas filiaciones políticas con el Gobierno venezolano. En declaraciones de su por entonces secretario de comunicación, González Pons, «vamos a unas elecciones ideológicas en las que vamos a tener que optar entre España o Venezuela, entre libertad sin ira o ira sin libertad». Así, en este encuentro se escuchó la canción de Jarcha ${ }^{51}$. En último término, si eliminamos las estrofas de este tema y tan solo cantamos o reproducimos por megafonía su estribillo, se amplifican sus posibilidades de instrumentalización. Este hecho puede explicar los dos ejemplos siguientes, de naturaleza contrapuesta. USTEA (Unión de Sindicatos de Trabajadoras y Trabajadores de Andalucía), sindicato vinculado a la educación en el sur de España, reivindicó la importancia de la educación pública empleando por megafonía dicha canción ${ }^{52}$. De la misma forma, «Libertad sin ira» fue el emblema de una concentración por la escuela concertada ${ }^{53}$.

Una de las continuidades más destacadas es la que asocia «Libertad sin ira» con la repulsa a la banda terrorista ETA, pasando de emplear de forma restrictiva "Libertad sin ira" como canción de la Transición a recordar «Libertad sin ira» como canción emblemática vinculada al asesinato de Miguel Ángel Blanco. En el cambio de siglo se produjo una repulsa por parte del Partido Popular, principal partido de la oposición, a determinadas políticas vinculadas al País Vasco de la primera y segunda legislatura de José Luis Rodríguez Zapatero al frente del Gobierno de España (2004-2008, 20082011). La canción de Jarcha fue escuchada y coreada en diferentes manifestaciones y concentraciones estrechamente vinculadas al Partido Popular contra el Gobierno a este respecto ${ }^{54}$.

Las lecturas críticas con el proceso y recuerdo de la transición democrática también han dedicado un espacio a "Libertad sin ira», pero con el objeto de destacar su naturaleza vinculada a los relatos celebratorios con el proceso de Transición. En su trabajo «Verdad sin ira. Repensar el silenciamiento del

51 «Mariano Rajoy arenga al PP juvenil sacudiendo lo suyo a Pablo Iglesias, Monedero, Errejón y los “caraduras" de Podemos», Periodista Digital, 24-1-2015, disponible en: https://bit.ly/2vrLrhY (fecha de consulta: 20-1-2019).

52 Un fragmento de dicha concentración de USTEA en Málaga en 2010 puede consultarse en YouTube, disponible en: https://www.youtube.com/watch?v=bcpeDs1q8eo (fecha de consulta: 20-1-2019).

53 Veáse en YouTube, disponible en: https://www.youtube.com/watch?v=87Vp7hZ-P-s (fecha de consulta: 18-1-2019).

54 Véase, por ejemplo, el uso de esta canción en la marcha del 10 de marzo de 2007 impulsada por el Partido Popular, disponible en YouTube: https://www.youtube. com/watch?v=fRmovn5XFIU (fecha de consulta: 3-1-2019). 
genocidio franquista», Pedro Piedras Monroy muestra su oposición a la "cultura de la Transición" a través de una crítica a las visiones celebratorias con este periodo en «Libertad sin ira»:

De los más niños a los más ancianos, todo el mundo conoce y ha tarareado en alguna ocasión este popero himno parahippie. Sus notas han corrido invariablemente ligadas a las imágenes más arquetípicas del relato épico de la heroica conquista de la democracia en España. [...] «Libertad sin ira» colonizaba machaconamente desde la televisión y la radio las mentes de los expectantes ciudadanos espańoles. Un toque sentido y un estribillo pegadizo bastaban para inocular un mensaje llamado a desactivar la memoria del genocidio y la represión franquista ${ }^{55}$.

La referencialidad intertextual a «Libertad sin ira», en este caso, se mueve mediante el rechazo a un himno que, según el autor, representa tan solo una parte de las narraciones de la Transición —entendidas como hegemónicasy que olvida la necesidad de una memoria histórica: «A la canción Libertad sin ira, escrita y aplaudida por los hijos de la represión, se va oponiendo en los últimos tiempos otra menos amable, menos voluntariosa, menos alegre, menos pegadiza y que no admite tan fácil acompañamiento de palmas. Esta canción que han empezado a cantar algunos nietos y bisnietos de la represión bien podría titularse "Verdad sin ira" ${ }^{56}$. Piedras Monroy incluye, al final de su artículo, un poema en el cual se desarrolla una paráfrasis de la canción a través del recurso de la parodia —entiéndase aquí parodia en su acepción no necesariamente vinculada a lo humorístico - en el cual denuncia las vejaciones y el genocidio ejercidos durante la Guerra Civil y el franquismo.

Durante los últimos diez años, la significación política de «Libertad sin ira» se ha resituado en España por parte de músicos, audiencias y ciudadanía a través de estrategias intertextuales sutiles, como la exclusión simbólica o la alusión, siendo dos casos paradigmáticos los del $15 \mathrm{M}$ o el procés catalán, respectivamente. El 15M, conocido como movimiento de los indignados (2011), acontecimiento de la historia más reciente de España de trascendencia política y social a nivel nacional e internacional, es un fenómeno de especial interés para nuestro objeto de estudio.

Germán Labrador ha analizado las concomitancias entre discursos y prácticas ciudadanas de la transición y del $15 \mathrm{M}$ en torno a las demandas de mayores conquistas democráticas. Así, pone su foco de atención en las

55 Piedras Monroy (2015): 34.

56 Ibid.: 35. 
relaciones entre el movimiento de los indignados y las movilizaciones de 1976 (año que coincide con la publicación de la canción «Libertad sin ira»), ya que comparten lecturas contrahegemónicas sobre una "cultura de la transición» — esto es, vinculada a la institucionalización de una serie de lecturas oficialistas sobre la transición a la democracia—, que el autor distingue de la «cultura en la transición", es decir, aquella articulada durante este periodo histórico. A través de un análisis del lema "Lo llaman democracia», Labrador sostiene que «este grito, en España, atraviesa dos épocas manteniendo continuas las claves de una comunidad hermenéutica sin continuidad sociológica definida. En él, se condensa una memoria alternativa de la transición, basada en la crítica utópica de la democracia por venir $\aleph^{57}$. Por su parte, en su trabajo sobre las relaciones entre música y política durante la crisis económica española entre 2011 y 2016, Fruela Fernández sostiene que el 15M se orientó, acorde con la lectura no oficialista de la Transición, en una doble dirección: por una parte, se revitalizó a los cantautores; por otra, se elevaron escenas que habían quedado, según la autora, silenciadas por el discurso oficial de la Movida, como el punk ${ }^{58}$. Fernández no menciona, sin embargo, referencias a «Libertad sin ira».

No debe sorprender el hecho de que esta canción no haya sido utilizada de forma significativa en movilizaciones vinculadas al $15 \mathrm{M}$, precisamente por esa revisión crítica de la Transición que este movimiento planteaba. A nuestro juicio, la omisión de este tema de Jarcha como canción emblemática en el movimiento de los indignados es otra forma de reapropiación política en música a través de la no inclusión, dado que toda selección de repertorios musicales obedece a motivaciones estéticas e ideológicas vinculadas a la creación de un canon o corpus de obras modélicas, algo especialmente evidente en este contexto.

Recientemente, Ángel Corpa, cantautor y líder de Jarcha, puso música a un poema de Benjamín Prado sobre el procés catalán titulado «Hablemos» (2017), grabando una canción y videoclip con el mismo nombre ${ }^{59}$. Sobre este texto, Corpa comenta:

[...] es un soneto que encontré un día en las redes y me llamó mucho la atención, porque hay un guiño además a «Libertad sin ira» y, según lo iba leyendo, me iba surgiendo la música y cuando terminé la canción estaba prácticamente acabada, a falta de unos retoques. Me gustaría plantear un cauce por el que puedan fluir la cantidad de sentimientos complejos y a veces encontrados que

\section{Labrador (2014): 54.}

58 Fernández (2017).

59 Ángel Corpa y Benjamín Prado: «Hablemos», disponible en YouTube: http://bit. ly/2vZhx4Y (fecha de consulta: 28/01/2019). 
llenan gran parte de la sensibilidad de la gente que habitamos Espańa, dentro de una situación muy compleja. Hacer un llamamiento a la concordia y al entendimiento mediante el diálogo siempre es un buen consejo ${ }^{60}$.

El carácter icónico de "Libertad sin ira» está representado en la canción grabada tanto por la alusión interfonográfica a esta emblemática canción — «con libertad, sin ira, como hermanos»_ en los versos como por el propio Ángel Corpa, quien encarna en su propia voz el recuerdo y la memoria de la Transición. Este hecho es reforzado por un videoclip en el cual se presentan escenas, planos y secuencias en los cuales la presencia del cantautor se intercala con imágenes misceláneas de las manifestaciones sobre el procés y recortes de prensa sobre la marcha de empresas de Cataluña. No faltan, tampoco, las manos blancas que, como se argumentó, operaron como un icono de las movilizaciones en torno al secuestro y asesinato de Miguel Ángel Blanco. Uno de los puntos culminantes del videoclip se produce cuando, tras el estribillo, se realiza una alusión musical ${ }^{61}$ instrumental al tema melódico principal de Els segadors (2'14'-2'24"), que es enlazada con el dibujo melódico del Himno de España (2'24'-2'40'). En este fragmento aparecen un niño y una niña de la mano, portando a sus espaldas, en forma de capa, sendas banderas de Cataluña y de España. A este respecto, cabe destacar cómo este resultado musical —una suerte de mash-up en el cual ambos himnos se mezclan simultáneamente en una canción- estuvo también presente, aunque por medio de la materialidad política de la auralidad $^{62}$ en vivo, en la Diada del 11 de septiembre de 2019. Durante la ofrenda floral a Rafael Casanova, mientras diversos cargos políticos del Parlament de Catalunya entonaban Els segadors, se escuchó, por medio de una megafonía instalada en un edificio cercano al acto oficial, el Himno de España.

\section{EPÍLOGO: ¿̇UN HIMNO PARA LA ESPAÑA DEMOCRÁTICA?}

Yo, cuando planteo una canción de cualquier tipo, fundamentalmente lo que busco es propiciar un cauce a través del cual fluyan [...] todos los sentimientos

${ }^{60}$ En Nuria Lozano: “Libertad sin ira” es lo más hermoso que me ha pasado», Las noticias de Cuenca, 27-12-2017, disponible en: http://bit.ly/38TuvzN (fecha de consulta: 19/12/2018).

61 Sobre la alusión musical como recurso intertextual, véanse Ogas (2010) y LópezCano (2018).

62 Sobre la naturaleza cultural, social y política del sonido, vinculada a los denominados sound studies, véase el trabajo compilador de Pinch y Bijsterveld (2012). 
que nos habitan en un momento determinado a los que somos potenciales oyentes de algún tema. Entonces, el que una canción se convierta en himno o no se convierta en himno, a mí es una cosa que particularmente no me va ni me viene porque, en definitiva, yo no soy dueño de eso. Una vez que he puesto la canción en el viento siento que deja de pertenecerme porque la harán suya, más o menos, las personas que la necesiten para algo. Esto ocurrió en su día con «Libertad sin ira»: fue una canción que pusimos en el viento en el año 1976. Quería ser básicamente una canción donde ondeasen de una forma decidida las libertades que demandábamos en aquellos momentos ${ }^{63}$.

En las palabras de Corpa se atisban tres aspectos fundamentales que sintetizan una parte importante de las relaciones entre música popular y política. Por una parte, esta canción popular opera como una suerte de artefacto cultural emblemático para la canalización individual de un sentir colectivo o una suerte de espiritu de época que facilita su identificación masiva. Por otro lado, está presente, de forma implícita, la barthesiana idea de «la muerte del autor", esto es, la que sugiere que el compositor o intérprete musical no tiene la última palabra en la construcción de los significados. Por último, derivado de lo anterior, se observa un énfasis decidido en la centralidad de ciudadanía, audiencias e instituciones para la reapropiación e instrumentalización personal, cultural y política en torno a la canción popular.

Aunque carezca de un carácter oficial como himno, la presencia y calado en la sociedad de "Libertad sin ira" a lo largo de las últimas cuatro décadas es altamente significativa. Ya sea mediante la interpretación vocal colectiva de la canción por parte de la ciudadanía, el uso del parafraseo de su letra con diferentes fines o mediante la emisión con altavoces de la grabación en concentraciones y manifestaciones, recurriendo a ella para la parodia, criticando su conformismo o no incluyéndola en los temas de otra Transición, ninguna canción se ha aproximado tanto a la representación de este mito fundacional de la nación moderna postfranquista como lo ha hecho este tema escrito por Armenteros, Baladés y Herrero e interpretado por Jarcha.

Conceptualizar una canción popular bajo la denominación de himno vinculado a un periodo de la historia reciente de España no está, por supuesto, exento de complejidades y contradicciones. El propio ejercicio de patrimonializar determinadas músicas para que estas queden inscritas a un territorio, ya sea por parte de instituciones dedicadas a la salvaguarda de las tradiciones inmateriales o por asociaciones culturales devotas de su estudio, acarrea paradojas, contradicciones discursivas y fragmentaciones

63 Véase nota 44. 
identitarias. Esto no implica, necesariamente, la aceptación de que lo que es representativo de un lugar nos represente a unos o a otros. Parece obvio entonces que, de manera análoga al modus operandi de la patrimonialización de la música, el hecho de que una canción constituya, a nivel oficial o simbólico, un himno, no implica que la ciudadanía, en su totalidad, se identifique o se sienta representada por los valores reflejados en sus letras o articulados por diferentes poderes políticos. Precisamente, la pluralidad de memorias y relatos contrapuestos sobre "Libertad sin ira", sus reapropiaciones diversas y lecturas intertextuales en distintos formatos, tanto como su negación o no inclusión, no hacen sino reforzar aún más su centralidad como himno disputado de la España democrática en constante negociación y redefinición.

\section{Bibliografía}

Alonso, C. (2010). Creación musical, cultura popular y construcción nacional. En C. Alonso et al. Creación musical, cultura popular y construcción nacional en la España contemporánea (pp. 39-56). Madrid: Instituto Complutense de Ciencias Musicales.

Ayats, J. (1997). Dos situaciones de expresión sonora colectiva: las manifestaciones en la calle y en los estadios deportivos. Trans: Revista Transcultural de Música, 1. Disponible en: https://bit.ly/3bwxWOH.

Baby, S. (2018). El mito de la transición pacífica: Violencia y política en España (1975-1982). Madrid: Akal.

Balfour, S. y Quiroga, A. (2007). The Reinvention of Spain: Nation and Identity since Democracy. Oxford: Oxford University Press. Disponible en: https://doi.org/10.1093/acprof:oso/9780199206674.001.0001.

Benedicto, J. A. (2015). «Y en esto llegó la crisis». Transformaciones y quiebra de la matriz cultural de la democracia española. En M. Pérez Ledesma e I. Saz Campos (coords.). Del Franquismo a la Democracia: 1936-2013 (pp. 175-204). Madrid: Marcial Pons.

Buch, E. (2001). La Novena de Beethoven. Historia politica del himno europeo. Barcelona: Acantilado.

- y Donin, N. (eds.). (2013). Du Politique en Analyse Musicale. Paris: VRIN.

— , Contreras, I. y Deniz Silva, M. (eds.). (2016). Composing for the State: Music in Twentieth-Century Dictatorships. New York: Ashgate. Disponible en: https://doi. org/10.4324/9781315573236.

Collado Seidel, C. (2016). Himnos y canciones: símbolos de identidad colectiva. En C. Collado Seidel (ed.). Himnos y canciones. Imaginarios colectivos, simbolos e identidades fragmentadas en la España del siglo XX (pp. 1-7). Granada: Comares.

Contreras, I. (2016). El Concierto de la Paz (1964): Three Commissions to Celebrate 25 Years of Francoism. En E. Buch, I. Contreras y M. Deniz Silva (eds.). Composing for the State: Music in Twentieth-Century Dictatorships (pp. 168-186). New York: Ashgate. 
Fernández, F. (2017). «Voy a empeñar la Edad de Oro»: historia, música y política en la crisis española (2011-2016). Romance Quarterly, 64 (3), 135-146. Disponible en: https://doi. org/10.1080/08831157.2017.1321344.

Fornaro Bordolli, M. (2012). Diálogos y resistencia: la presencia de la música espańola en la creación popular uruguaya. Cuadernos de Música Iberoamericana, 24, 63-89.

— (2014). Músicas y proyectos de país durante la dictadura uruguaya (1973-1985). Resonancias: Revista de Investigación Musical, 18, 49-67. Disponible en: https://doi. org/10.7764/res.2014.34.4.

Fouce, H. (2006). El futuro ya está aqui. Música pop y cambio cultural. Madrid: Velecío.

- (2009). De la agitación a la Movida. Políticas culturales y música popular en la Transición española. Arizona Journal of Hispanic Cultural Studies, 13, 143-153. Disponible en: https://doi.org/10.1353/hcs.0.0066.

— y Del Val, F. (2013). La Movida: Popular Music as the Discourse of Modernity in Democratic Spain. En H. Fouce, Héctor y S. Martínez (eds.). Made in Spain. Studies in Popular Music (pp. 125-134). New York: Routledge.

García, A. C. (2017). Libertad sin ira: Secretos y Curiosidades Martianas. Caracas: Letras Latinas.

García Peinazo, D. (2012). La Nueva Canción Latinoamericana en El Socialista y Mundo Obrero. Música y discurso político durante la transición (1973-1982). Cuadernos de Música Iberoamericana, 24, 113-142.

- (2014). Música, prensa y argumentaciones políticas de la transición española en los órganos de expresión del PCE y el PSOE (1977-1982). Ensayos: Revista de la Facultad de Educación de Albacete, 29 (2), 95-113.

- (2017). Rock andaluz: Significación musical, identidades e ideología en la España del tardofranquismo y la Transición (1969-1982). Madrid: Sociedad Española de Musicología. Disponible en: https://doi.org/10.2307/24878588.

García Salueña, E. (2017). Música para la libertad. Nuevas tecnologias, experimentación y procesos de fusión en el rock progresivo de la España de la Transición: el eje noroeste. Avilés: Norte Sur.

Grau Rebollo, J. (2015). «Oh, That's So Typical!». Discussing Some Spanish «Authentic» Essential Traits. En T. Fillitz y A. J. Saris (eds.). Debating Authenticity. Concepts of Modernity in Anthropological Perspective (pp. 91-107). New York; Oxford: Berghahn.

Holguín, S. (2017). Music and Nationalism. En J. Moreno-Luzón y X. M. Núñez Seixas (eds.). Metaphors of Spain: Representations of Spanish National Identity in the Twentieth Century (pp. 219-238). New York: Berghahn. Disponible en: https://doi.org/10.2307/j. ctvw04dd1.14.

Labrador, G. (2014). ¿Lo llamaban democracia? La crítica estética de la política en la transición española y el imaginario de la historia en el 15-M. Kamchatka: Revista de Análisis Cultural, 4, 11-61. Disponible en: https://doi.org/10.7203/KAM.4.4296.

Lacasse, S. (2018). Toward a Model of Transphonography. En L. Burns y S. Lacasse (eds.). The Pop Palimpsest: Intertextuality in Recorded Popular Song (pp. 9-60). Michigan: University of Michigan Press.

López-Cano, R. (2012). Lo original es la versión: covers, versiones y originales en la música popular urbana. ArtCultura: Revista de História, Cultura e Arte, 14 (24), 81-98. 
- (2018). Música Dispersa: Apropiación, influencias, robos y remix en la era de la escucha digital. Barcelona: Musikeon Books.

Martí, J. (2013). Claves del pensamiento martiano. Ensayos políticos, sociales y literarios. Madrid: Editorial Verbum.

Martinelli, D. (2017). Give Peace a Chant. Popular Music, Politics and Social Protest. Vilna: Springer. Disponible en: https://doi.org/10.1007/978-3-319-50538-1.

Medina, A. (2010). Acotaciones musicales a la transición democrática en España. En C. Alonso et al. Creación musical, cultura popular y construcción nacional en la España Contemporánea (pp. 267-282). Madrid: Instituto Complutense de Ciencias Musicales.

Moore, A. F. (2012). Song Means: Analysing and Interpreting Recorded Popular Song. Surrey y Burlington: Ashgate.

O'Connell, J. M. (2010). An Ethnomusicological Approach to Music and Conflict. En J. M. O’Connell y S. E. Castelo-Branco (eds.). Music and Conflict (pp. 1-16). Springfield: University of Illinois Press.

Ogas, J. (2010). El texto inacabado: tipologías intertextuales, música española y cultura. En C. Alonso et al. Creación musical, cultura popular y construcción nacional en la España contemporánea (pp. 233-252). Madrid: Instituto Complutense de Ciencias Musicales.

Pasamar, G. (2018). Los relatos escépticos sobre la Transición española: origen y claves políticas e interpretativas. Les Cahiers de Framespa, 27. Disponible en: https://doi. org/10.4000/framespa.4738.

Pérez-Villalba, E. (2007). How Political Singers Facilitated the Spanish Transition to Democracy, 1960-1982. The Cultural Construction of a New Identity. New York: The Edwin Mellen Press.

Petit, J. M. (1983). Crónica de un «Obeliscazo». Jaque: Revista Semanario, 1 (3), 16-17.

Piedras Monroy, P. (2015). Verdad sin ira. Repensar el silenciamiento del genocidio franquista. En F. Godicheau (ed.). Democracia Inocua. Lo que el posfranquismo ha hecho de nosotros (pp. 33-52). Madrid: Postmetrópolis. Disponible en: https://bit. ly/37qmW2k.

Pinch, T. y Bijsterveld, K. (2012). The Oxford Handbook of Sound Studies. New York: Oxford University Press. Disponible en: https://doi.org/10.1093/oxfordhb/978019 5388947.001.0001.

Sábada Garraza, T. (2004). Enfoques periodísticos y marcos de participación política. Una aproximación conjunta a la teoría del encuadre. Politica y Sociedad, 41 (1), 65-76.

Sehrt, J. y Reckling, T. (2013). Democracy in the Museum. The Fundation and Permanent Exhibition of the Museo Adolfo Suárez y la Transición. International Journal of Iberian Studies, 26 (1), 103-111. Disponible en: https://doi.org/10.1386/ijis.26.1-2.103_3.

Solís Marquínez, A. T. (2018). La figura de Gustav Mahler en la España de la Transición: un ejemplo de construcción cultural ligada al guerrismo. En M. López-Fernández (ed.). Música en Sevilla en el siglo XX. Granada: Libargo.

Tagg, P. (2013). Music's Meanings. A Modern Musicology for non-Musos. New York; Huddersfield: The Mass Media Music Scholars' Press.

Urbain, O. et al. (2008). Music and Conflict Transformation. Harmonies and Dissonances in Geopolitics. London: I. B. Tauris. 
Val, F. del (2017a). Rockeros insurgentes, modernos complacientes: un análisis sociológico del rock en la Transición (1975-1985). Madrid: Datautor; Fundación de la Sociedad General de Autores y Editores.

- (2017b). Sing as you talk: politics, popular music and rock criticism in Spain (19751986). Journalism, 1, 1-20. Disponible en: https://doi.org/10.1177/1464884917719586.

Valenzuela, E. T. (2014). Dios, Marx... y el MAPU. Santiago: LOM Ediciones. 